\title{
Dimensões críticas das políticas públicas
}

\author{
Critical dimensions of public policies
}

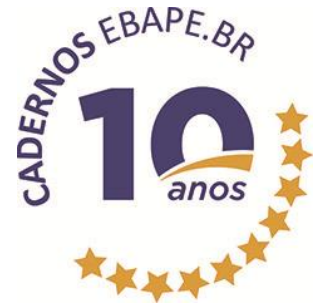

Francisco Fonseca ${ }^{1}$

\begin{abstract}
Resumo
Este artigo elabora reflexão crítica, em forma de ensaio, sobre algumas dimensões negligenciadas ou pouco desenvolvidas nas principais abordagens teóricas das "políticas públicas". Metodologicamente, questões conceituais são articuladas ao debate público, a começar pela própria revisão do termo "política pública". Conclui-se que questões como o papel do conflito, de naturezas variadas; dos constrangimentos advindos do modelo de acumulação capitalista $e$ do sistema político (brasileiro, no caso) quanto à efetivação de reformas transformadoras; e do poder de veto da mídia e de outros atores devem ser revalorizados e ressignificados, com vistas a uma interpretação mais profícua do papel das "políticas públicas". Particularmente, essas dimensões podem contribuir para a compreensão das "políticas públicas" na sociedade brasileira: suas características, funções e impactos.
\end{abstract}

Palavras-chave: Políticas Públicas. Dimensões Críticas. Debate Público. Conflitos. Poder de Veto.

\begin{abstract}
This article is a critical reflection, in essay form, about some dimensions neglected or poorly developed in the main theoretical approaches of "public policies". Methodologically, conceptual issues are related to the public debate, starting from the review of the term "public policy" itself. We conclude that issues such as the role of conflict, with various natures; the constraints due to the capitalist accumulation model and the political system (the Brazilian, in this case) with regard to the effectuation of transformative reforms; and the veto power of mass media and other actors must be revalued and resignified, aiming at a more fruitful interpretation of the role of "public policies". Particularly, these dimensions may contribute to the understanding of "public policies" in the Brazilian society: their characteristics, functions, and impacts.
\end{abstract}

Keywords: Public Policies. Critical Dimensions. Public Debate. Conflicts. Veto Power.

\section{Introdução}

As práticas governamentais e o debate acadêmico contemporâneos têm sido marcados pela predominância e difusão de um conceito amplo, fugidio e pouco fundamentado: o de "políticas públicas". Interpretado teoricamente de variadas formas e, por vezes contrastantes, e apercebido social e politicamente com sentidos (e expectativas) distintos, tal conceito necessita de reflexão crítica para que se tenha exata noção sobre o que ele representa e qual seu papel e impacto na sociedade.

Artigo submetido em 22 de maio de 2013 e aceito para publicação em 03 de setembro de 2013.

1 Doutor em História Social pela Universidade de São Paulo (USP); Professor do curso de graduação e pós-graduação em Administração Pública da Fundação Getulio Vargas de São Paulo/Eaesp. Endereço: Rua Itapeva, 474, 7. Andar - Departamento de Gestão Pública, CEP 01332-000, São Paulo - Capital, Brasil. E-mail: francisco.fonseca@fgv.br 
Deve-se ressaltar que a difusão sem critério desta expressão torna toda e qualquer ação governamental, incluindo-se as atividades elementares dos governos, associada à existência daquilo que se chama de "política pública". Mesmo em termos conceituais, uma definição clássica e genérica, como "o governo em ação", mais confunde do que esclarece acerca de seu significado. Afinal, o Estado e, no interior deste, o governo, pode "entrar em ação" de forma reativa, sem planejamento, e mesmo sem orçamento e recursos humanos, uma vez que os móveis das ações governamentais ocorrem por diferentes demandas, razões e circunstâncias. Ou, ao contrário, pode ocorrer após a maturação de um programa por meio de especialistas, que instilam o tema nos governos, ao lado de pressões sociais de variadas naturezas e formas de expressão. Trata-se, portanto, de um processo complexo, multicausal e multidirecional.

Mais ainda, as políticas e os programas governamentais, genericamente intitulados "políticas públicas", inscrevem-se nos sites dos governos e do poder público como um todo e são tidos como "naturais" pela percepção pública do cidadão comum, mesmo que formalmente não se adote essa denominação. São, assim, destituídas de conflitos e vetos.

As seções deste texto, originalmente publicadas como artigo no portal Carta Maior, são aqui retrabalhas, redefinidas e complementadas, formando um todo que objetiva refletir criticamente sobre os usos, omissões e abusos do conceito de "políticas públicas".

Para tanto, são discutidos os seguintes aspectos: os perigos (armadilhas) de não se ressaltarem os conflitos, que são o cerne das "políticas públicas", quando se analisam programas governamentais; os alcances e, sobretudo, limites das "políticas públicas" perante o modelo de acumulação; os constrangimentos advindos do sistema político à formulação e implementação de "políticas públicas"; o papel da mídia como ator político e ideológico, sobretudo quanto aos vetos que os órgãos de comunicação interpõem a determinadas "políticas públicas" (como representantes das classes médias e superiores); e, por fim, questões conjunturais relativas ao debate político em que as "políticas públicas" aparecem como protagonistas.

Portanto, neste artigo, busca-se analisar diversos temas, problemas e questões relacionados ao conceito - que se confunde com mera terminologia - de "políticas públicas". Não será feito, contudo, na perspectiva de um inventário das linhagens teóricas que interpretam e reinterpretam o conceito, uma vez que se situa na fronteira entre problemas teóricos e o debate público. Adota-se, dessa forma, caráter ensaístico, uma vez que a reflexão original fora voltada ao debate público, além de representar uma tentativa de ir além do enquadramento predominante quando se reflete sobre "políticas públicas", observando-se assim equívocos, negligências e contradições.

\section{A Ocultação dos Conflitos como Armadilha à Compreensão das "Políticas Públicas" e às Reformas Sociais}

A expressão "políticas públicas" tornou-se de domínio comum nos últimos anos e frequente nos discursos eleitorais e governamentais, no debate público, na academia e nas organizações politicamente organizadas da sociedade. Conforme aludido, é definida de forma minimalista como "o governo em ação", entre diversas outras definições possíveis, e sua viabilização só é possível se houver um projeto definido e a mobilização de recursos orçamentários, humanos, informacionais, legais e logísticos.

Tal profusão de espaços em que é invocada, muitas vezes de forma distinta, faz dessa expressão algo com aparência "neutra" e "consensual", pois supostamente voltada ao "bem público" e ao "bem-estar social". Aparentemente ninguém discordaria de programas - das mais variadas ordens - cujos objetivos seriam minorar e/ou resolver problemas que afetam grande número de pessoas e, consequentemente, o país.

Pois bem, essa imagem "generosa" das "políticas públicas", em que todos ganham e ninguém perde ou discorda - a referida "naturalização" -, é não apenas falsa como representa verdadeira armadilha à compreensão de seu significado, na medida em que encobre disputas de poder. 
O pensamento conservador, representante de majoritários estratos médios e superiores da sociedade brasileira, largamente expresso pela grande mídia, tende a se aproveitar desses supostos consensos como forma de imprimir - aberta ou sorrateiramente - suas demandas.

Mais ainda, no chamado "ciclo das políticas públicas" - agenda, formulação, implementação e avaliação -, cada etapa permite intervenções distintas dos grupos que se sentem, real ou imaginariamente, atingidos. Isso implica a adoção de "vetos", que se dão de formas distintas dependendo da correlação de forças e dos recursos de poder dos atores em disputa.

Em outras palavras, no mundo real da política, "políticas públicas" expressa uma infindável teia de interesses, que congrega desde a capacidade técnica de elaborar e implementar um dado programa, as contendas orçamentárias, e as combinações e recombinações de interesses em cada etapa do ciclo $^{2}$. A imagem e a percepção do cidadão comum sobre um determinado projeto e mesmo sobre um determinado governo são, dessa forma, resultado desse complexo processo, mas que tem na mídia - fortemente conservadora e oligopolizada, como se verá mais abaixo - um ator fundamental em razão de sua capacidade de intermediar relações sociais aproveitando-se da zona cinzenta que orbita entre interesses privados, que representa, e a "esfera pública", que intenta representar à sua maneira.

Tudo somado, há de se ter muita cautela, sobretudo quando grupos progressistas ganham eleições, como é o caso de diversos prefeitos eleitos em 2012, na medida em que o enfrentamento de problemas de grande magnitude como "mobilidade urbana" e "habitação", entre outros, implicam necessariamente conflitos. Conflitos que se expressam na dotação orçamentária conferida a uma dada "política pública", no número e qualificação de servidores envolvidos em sua consecução, no aparato legal e institucional mobilizado, entre outros aspectos.

Nestes dois exemplos, respectivamente a poderosa indústria automobilística - e sua cadeia produtiva - e os grandiosos interesses imobiliários procuram vetar toda e qualquer medida e, sobretudo, programas governamentais consistentes que inibam seus negócios. São, portanto, "pontos de veto", cujo conhecimento é fundamental, mesmo no nível subnacional. Afinal, os avanços nos códigos legais (caso, por exemplo, do Estatuto das Cidades), nas instituições de planejamento e controle (sobretudo a Corregedoria Geral da União e o Ministério Público), particularmente em nível federal e vivenciados no país como um todo, não impediram o crescimento vertiginoso do automóvel como opção prioritária dos governos, assim como da apropriação do território pela "indústria da especulação imobiliária".

Como se fossem dois vetores em sentido contrário, os avanços legais/institucionais, de um lado, e o privatismo do automóvel e da especulação imobiliária, de outro, têm, até agora, demonstrado clara vitória destes últimos. Muitos dos males de nossas cidades provêm dessa estrutura de poder pouco confrontada política e institucionalmente, apesar da existência de "políticas públicas", que necessitam ser mais bem analisadas.

Os governos reformadores, dos quais particularmente os pobres muito esperam, como o demonstram os mapas eleitorais, somente será "progressista", ideia-força pela qual se elegeram, se, mesmo no âmbito municipal, houver protagonismo capaz de conhecer e enfrentar os interesses estabelecidos, notadamente na ocupação do espaço: pelo automóvel particular e pelas habitações de classe média e de luxo, no contexto de toda sorte de apropriação desigual do território.

O fato de o âmbito municipal não ter competência legal para o enfrentamento de diversos problemas urbanos e metropolitanos é atenuado em virtude de as grandes cidades - espécie de "Cidades-Estado" - terem poder político, econômico e social capaz de enfrentar interesses corporativos empresariais, assim como servir de

${ }^{2}$ Mesmo que o enquadramento em forma de "ciclo", na análise das políticas públicas, seja questionável, conforme visto, é possível compreender que em cada etapa - que, por vezes se sobrepõem -, os perdedores retornam com o firme propósito de minimizar suas perdas. 
"ponta de lança" ao próprio governo federal. O conhecimento acerca do que envolve as "políticas públicas" permite-nos avançar nessa direção.

Sair da armadilha das "políticas públicas" supostamente "consensuais" e "generosas" - discurso caro aos grupos sociais representantes das classes médias e superiores, mesmo que de forma subliminar - é fundamental aos governos progressistas e aos intelectuais reformadores, uma vez que os atores que defendem interesses cristalizados têm grande capacidade de vetar mudanças sociais profundas, em nome do "bem comum", reitere-se. Como se viu ao longo da história, é grande o perigo de, em torno da ideia de "bem comum", os grandes interesses vetarem os dispositivos mais progressistas ${ }^{3}$. No caso da mobilidade urbana, corredores de ônibus e ampliação da frota destes tendem a ser aceitos por esses atores, desde que a estrutura de incentivos à indústria automobilística e o livre trânsito do automóvel não sejam tocados. No caso do setor imobiliário, em que o poder público municipal tem maior autonomia, historicamente parte dos vereadores é financiada por ele. As leis de zoneamento tendem a ser lenientes com esses grandes interesses: basta observar a transformação dos bairros operários em condomínios de alto luxo na cidade de São Paulo, assim como a intensa e progressiva expulsão dos pobres das zonas centrais para as extremas periferias, incluindo-se a região de mananciais, fenômeno que continua vigente nos dias de hoje.

Desse modo, estratégias diversas são possíveis aos governos, sem desconsiderar a dinâmica eleitoral advinda do multipartidarismo flexível vigente, desde que se cumpram os compromissos de mudança: priorização do transporte coletivo com desestímulo/punição progressivos ao transporte individual; utilização do Estatuto das Cidades como referência para a reforma urbana; apoio à participação popular; descentralização, por meio das subprefeituras, o que implica orçamento, recursos humanos, capacitação técnica e participação das populações locais nas tomadas de decisão; transparência nas ações governamentais; e capacidade tecnopolítica para enfrentar os grandes interessantes dominantes, entre outros.

Esses dois exemplos analisados sintetizam a complexidade de se governar as grandes cidades brasileiras, e, mais que isso, demonstram como o conceito de "políticas públicas" necessita ser qualificado, e, sobretudo, compreendidos os interesses constituídos - capazes de interferir em todas as etapas do ciclo das "políticas públicas".

Dessa forma, a suposta "unanimidade" das "políticas públicas", uma vez que objetivaria o referido "bem comum", encobre, no chamado "ciclo das políticas públicas", seu caráter conflitivo quanto aos interesses em disputa e os vetos, por meios distintos, advindos dos grupos sociais que se sentem, real ou imaginariamente, prejudicados. Tais conflitos podem assumir conotações de embate de classes sociais, por mais que conceituar classes e seus embates implique novo esforço analítico.

Finalizando esta seção, pode-se dizer que "políticas públicas" podem ser caracterizadas como um processo de decisão política que se materializa em objetivos com resultados esperáveis, normalmente vinculados à transformação de uma dada realidade, com vetores distintos, e que envolvem: a) técnicos estatais e não governamentais, burocratas e políticos (tomadores de decisão); b) atores distintos (com "recursos de poder" assimétricos), cenários e conjunturas (por vezes voláteis); c) capacidade e viabilidade de o Estado disponibilizar recursos orçamentários, humanos, legais e logísticos; d) mecanismos de mensuração dos resultados. A teoria do "ciclo de políticas públicas" (agenda, formulação, implementação e avaliação) pode ser invocada para fins mais pedagógicos do que propriamente reais, uma vez que a realidade não apenas é mais complexa do que faz supor estas etapas, como também mais "confusa" - à luz da perspectiva de C. Lindblom (1959).

${ }^{3}$ A reação às mudanças sociais e políticas progressistas foi analisada brilhantemente por Albert Hirschman (1985). Quanto ao papel dos grupos conservadores - representados pela grande mídia durante a Constituinte de 1987/88 - reagentes à introdução de direitos sociais e políticos aos trabalhadores, ver Francisco Fonseca (2005). 


\section{"Políticas Públicas" no Capitalismo Contemporâneo: Alcances e Limites}

Pouco discutido pelos estudos predominantes em "políticas públicas", o modelo de acumulação capitalista contemporâneo, intitulado "flexível" justamente por flexibilizar os fatores produtivos, necessita ser analisado como dimensão crucial ${ }^{4}$.

De forma panorâmica, algumas características exemplificam essa definição: complexa e perversa combinação entre o capital financeiro e o produtivo; inédito controle do Capital sobre: a) a circulação, por meio do estabelecimento de nichos de produção e consumo, da eliminação de estoques (just in time) e do incrível aprofundamento da "obsolescência programada", entre outras estratégias; e b) o trabalhador, pela via da diminuição maciça da força de trabalho nos três setores produtivos: primário, secundário e mesmo o terciário, embora, neste, em menor proporção. Em outras palavras, no capitalismo contemporâneo, vigente fortemente desde os anos 1980, produz-se cada vez mais (bens e serviços) com cada vez menos pessoas: daí o clássico tema, não superado, do "desemprego estrutural tecnológico" e da precarização do "trabalho", uma vez que este é substituído vigorosamente por "ocupações" informais. Mesmo nos setores tipicamente ocupados pelas classes médias superiores, caso da Administração de Empresas, a taxa de rotatividade é incrivelmente alta, levando seus profissionais a se tornarem "consultores", por conta própria, de uma infinidade de atividades, muitas das quais questionáveis quanto à sua utilidade social. No Brasil, a Consolidação das Leis do Trabalho (CLT) vem sendo corroída ano a ano pela chamada "pejotização" da mão de obra, uma vez que vastos segmentos de trabalhadores são obrigados a se constituir como pessoas jurídicas (PJ) como forma de vender sua força de trabalho, o que implica estar alijado de qualquer direito trabalhista. A "pejotização" é mais uma demonstração da preponderância, no caso brasileiro, do amplo domínio do trabalho pelo Capital, ainda que sorrateiro, na medida em que não se derrogou "formalmente" a CLT, mas o tem feito pelas bordas. Além do que, a pejotização - terminologia cada vez mais conhecida por amplos segmentos da força de trabalho - trata legal e institucionalmente o indivíduo como empresa, o que implica dupla perversidade quanto ao tratamento do trabalhador: pelo capital e pelo Estado.

Embora o modelo de acumulação não se constitua de forma exatamente igual em todos os países e regiões, por motivos que vão desde sua histórica inserção produtiva às reações dos trabalhadores, trata-se de uma variável (entre tantas outras) chave, cujas exemplificações acima são apenas uma amostra.

Para diversos analistas e agentes estatais, as "políticas públicas" seriam um antídoto eficaz por justamente mobilizar as forças do Estado no sentido de impedir a "barbárie do Capital".

Sem desconsiderar que vontade política, mobilização social, investimento público (orçamentário, de pessoal, legal e logístico) e regulação estatal - elementos constitutivos das "políticas públicas" - são fundamentais à reversão de situações de desigualdade, ao contrário, deve-se indagar a respeito dos limites de seus efeitos.

Vejamos o caso emblemático da contradição entre "obsolescência programada" - um dos elementos nucleares da acumulação flexível do Capital - e "políticas públicas" ambientais, cada vez mais cruciais à preservação do planeta e consequentemente das espécies. O Capital tem ampla liberdade, no capitalismo, para organizar a acumulação: a substituição da durabilidade dos produtos por sua obsolescência, programada e gerenciada cientificamente, embora não seja novidade na história capitalista, jamais encontrou ambiente tão fértil como na vigência ideológica do neoliberalismo, a partir dos anos 1970/80, quando chegou ao ápice esse processo que perdura até os dias de hoje. O exemplo dos aparelhos tecnológicos de consumo doméstico, tais como os referentes à informática e aos celulares, é marcante, pois constituídos de substâncias altamente poluidoras e de vida útil que tem como regra a fugacidade. A quebra (obsolescência) datada desses aparelhos em um ou dois anos expõe os claros limites do Estado perante o Capital em perspectiva internacional. Qualquer tentativa de interferência do Estado e de organizações internacionais, como a OIT e outras (e menos ainda dos sindicatos) no processo produtivo empresarial quanto aos princípios basilares da produção

\footnotetext{
${ }^{4}$ Flexível por se contrapor à chamada "rigidez" do modelo fordista no tocante aos fatores produtivos.
} 
contemporânea é prontamente rechaçado como "intervenção espúria". Mais ainda, o aparato jurídico é francamente protetor do "empreendedorismo" (tido e havido como schumpeteriano), da "inovação", da "propriedade" e da "iniciativa individual" - marcos do discurso ideológico contemporâneo -, o que contraria a perspectiva do "interesse coletivo" em preservar as bases mínimas da solidariedade e da preservação ambiental. O Estado é, portanto, limitado "estruturalmente", como mostra Claus Offe, ao observar quatro condicionantes estabelecidos pelo modelo de acumulação capitalista à atuação do Estado:

a) A privatização da produção: o poder público está estruturalmente impedido de organizar a produção material segundo seus próprios critérios 'políticos'. [...] b) Dependência dos impostos: o poder público depende, indiretamente, através de mecanismos do sistema tributário, do volume da acumulação privada. [...] c) A acumulação como ponto de referência: como o poder estatal depende do processo de acumulação capitalista, sem ser ele mesmo capaz de organizar este processo, o interesse supremo e mais geral dos detentores do poder do Estado consiste em manter as condições de exteriorização de seu poder através da constituição de condições políticas que favoreçam o processo privado de acumulação. [...] d) A legitimação democrática: [...] O exercício do poder através dos mecanismos democrático-representativos da formação das vontades e da regulamentação dos conflitos tem o sentido, no contexto do Estado constitucional burguês, de assegurar de forma politicamente duradoura - e não somente através de preceitos constitucionais - a delimitação da esfera privada e da esfera de liberdade econômica, de forma a defender essa esfera de liberdade de possíveis intrusões por parte do Estado.

[...] Em outras palavras: o Estado capitalista está sujeito a uma dupla determinação do poder político - segundo sua forma institucional, este poder é determinado pelas regras do governo democrático-representativo; segundo o seu conteúdo, é determinado pelo desenvolvimento e pelos requisitos do processo de acumulação. (OFFE, 1984, p. 124-125, grifo do autor).

Não foi diferente na era fordista-keynesiana, embora o vetor político/econômico (constituição de sociedades de produção e consumo de massa) e o contexto ideológico (disputas entre liberalismo derrotado, nazifascismo, socialismo e social democracia) fossem quase que opostos. No Brasil, embora a agenda de direitos se confundisse com a revolução industrial (anos 1940 em diante), o processo foi semelhante, guardadas as inúmeras particularidades.

Pois bem, a contradição entre a predominância de produtos, os mais diversos (não é diferente no caso do automóvel), marcados para definhar, e a necessidade que o planeta tem, notadamente a biosfera, de se recuperar da incessante prospecção de recursos naturais, demonstra os claros limites das "políticas públicas". Observe-se que a agenda ambiental é fortemente travada, em escala global, justamente pelo fato de os interesses do Capital, por vezes imiscuídos aos dos Estados Nacionais, se sobreporem aos das pessoas e das comunidades, mesmo quando a comunidade é o planeta ${ }^{5}$.

Outro exemplo marcante refere-se ao trabalho, como já mencionado, uma vez que não apenas o número de trabalhadores "necessários" à reprodução do Capital é cada vez menor, como também, dependendo do setor que se observe, o próprio número de consumidores pode ser diminuto. Tal como demonstrado por autores como Harvey (1990), Rifkin (1995) e outros, o Capital Global necessita de poucos trabalhadores (daí a emergência de empresas que não fabricam nada, apenas articulam de forma complexa o processo produtivo em escala global e dão aos produtos uma marca) e de poucos consumidores, que, contudo, tenham um padrão de renda e de consumo extremamente alto e fugaz. Tal fugacidade - fortemente apoiada nas modernas técnicas de propaganda e de indução ideológica ao consumo, ancoradas no sistema midiático, em sentido lato

\footnotetext{
${ }^{5}$ A filmografia contemporânea tem exposto, de forma significativa, o poder do Capital perante os Estados, mesmo (ou sobretudo) os tidos como "desenvolvidos", que teriam sido capturados pelos interesses empresariais: os filmes-denúncia The Corporation, Enron, Inside Job e boa parte da obra de Michael Moore, entre inúmeros outros, expressam, do ponto de vista dos países centrais do capitalismo, as consequências nefastas do modelo de acumulação flexível e, consequentemente, os limites das "políticas públicas".
} 
- faz da rotatividade do consumo num círculo pequeno o motor da exclusão social do trabalho e da barbárie ambiental. A "corrosão do caráter", com toda sorte de consequências individuais e sociais deletérias, como mostra Richard Sennett (1998), é o resultado mais notório dessa psicose coletiva envolvida nesse processo.

Reafirme-se que cada país, em razão da estrutura e inserção histórica de suas economias e de sua trajetória, instituições e capacidade de mobilização social refaz, de distintas formas, esse processo estrutural. Contudo, os eixos estruturantes estão colocados, limitando e circunscrevendo fortemente as alternativas.

Mesmo no Brasil, que na última década vem ostentando índices impressionantes de empregabilidade formal, esse processo não é diferente. Se são marcantes políticas como a elevação real do salário mínimo, a ampliação inédita do crédito, o estímulo ao consumo interno e a transferência de renda; no contexto de universalização de políticas sociais, deve-se ter clareza quanto aos seus limites. Assim, se a empregabilidade com carteira assinada é significativa, uma vez que as quebras de recordes em contratações são louváveis e inéditas, ainda assim não se supera o altíssimo grau de informalidade da economia brasileira. Além do que, os empregos são baseados em baixos salários e baixa qualificação e só ocorrem pela combinação entre vontade política em diminuir a exclusão e a desigualdade - móvel da "política pública" - com um estoque de empregos historicamente muito baixo. Tal estoque permite grande elevação na formalização - dado o deficit histórico -, porém não altera a estrutura do mercado de trabalho e da produção informal.

Esses exemplos, entre tantos outros, exteriorizam limites concretos da ação do Estado perante o Capital, pois, como vimos, este define os parâmetros da produção e da circulação e, cada vez mais, da organização do trabalho - o que é extremamente impactante -, uma vez que são (a produção e a circulação) o núcleo da reprodução do Capital.

Essa constatação não significa diminuir o papel das "políticas públicas" nem em termos conceituais nem empíricos, haja vista as transformações que estão em curso no Brasil contemporâneo. Significa, na verdade, analisar seus alcances e limites com vistas à compreensão do que cabe às "políticas públicas" estatais e do que cabe à luta política da sociedade politicamente organizada.

Desse modo, a chamada "radicalização da democracia" corresponde à ampliação crescente dos espaços de participação e deliberação nas arenas decisórias, institucionais e sociais; à tradutibilidade das linguagens oficiais herméticas, a começar pelo orçamento; ao aprofundamento da transparência decisória; à revisão do oligopólio da mídia (como veremos abaixo); entre tantas outras reformas possíveis. Tudo isso parece um caminho possível com vistas à revisão de prioridades do Estado: em sua forma (a democracia "radicalizada") e em seu conteúdo (as "políticas públicas").

Deve-se aqui retomar uma das máximas maquiavelianas, isto é, que "para mudar a realidade, há de ser realista". Tal assertiva parece especialmente válida para o pensamento acadêmico, para os ativistas políticos e sociais e para os administradores públicos, isto é, para aqueles que podem, cada qual a seu modo, transformar a realidade dada.

\section{Travas do Sistema Político às “Políticas Públicas" Transformadoras}

Outra dimensão fundamental à análise das "políticas públicas", igualmente esquecida, refere-se às travas do sistema político brasileiro à elaboração e implementação de "políticas públicas" transformadoras. Ressalte-se que, como mencionado acima, embora haja limites estruturais advindos do modelo de acumulação, não apenas há espaço para a ação do Estado no sentido de alterar regras, induzir comportamentos e transformar realidades, como a relação entre estrutura econômica (modelo de acumulação) e ação política ("políticas públicas", entre outras ações) não é uma equação estática e necessariamente aprisionada ao passado. Há uma espécie de linha móvel limítrofe entre ambas que levou à produção intelectual do que se denomina "variedades de capitalismo" (ver HALL e SOSKICE, 2001). 
O sistema político brasileiro, especificamente, foi estruturalmente moldado pela ditadura militar e jamais alterado significativamente desde a redemocratização. Algumas de suas características são: multipartidarismo extremamente flexível e pouco representativo; financiamento misto (público e privado), mas que, na prática, é largamente "privatizado" por meio do denominado "caixa 2"; infidelidade partidária (apenas recentemente minorada por decisão do Tribunal Superior Eleitoral); acesso institucional ao rádio e à televisão franqueados a todos os partidos com representação federal, independentemente de sua real representatividade (os partidos chamados "de aluguel" têm pequena representação parlamentar e todas as benesses do sistema político); toda sorte de casuísmo, tal como a coligação nas eleições proporcionais, que implica o voto num partido ou candidato e a eleição de outro, em razão da contagem do quociente eleitoral, entre outros; baixa transparência quanto ao uso dos recursos públicos (também recentemente minorada com a Lei de Acesso às Informações Públicas); lógica da coalizão para governar, ou melhor, para obter maioria no Parlamento, com impactos diretos na (in)coerência das "políticas públicas" e nos resultados eleitorais, uma vez que, usualmente, partidos derrotados participam de coalizões de governo capitaneadas pelos partidos vencedores; desenho eleitoral que concede carta branca do eleito ao representante - tornando o mandato "propriedade" deste - e o distancia de seus representados (a aludida reinterpretação da fidelidade partidária, pelo TSE, amenizou essa prática, mas ainda assim não a eliminou); baixo poder conferido ao Parlamento, tornando-o "despachante" de interesses paroquiais e corporativos; desbalanceamento na proporcionalidade federativa no Congresso Nacional no contexto do confuso bicameralismo; entre outras.

A emenda da reeleição aos chefes do Poder Executivo, que golpeou as regras do jogo vigentes em seu pleno funcionamento ${ }^{6}$, contribuiu ainda mais para as mazelas do sistema político brasileiro, pois: mudou profundamente as regras do jogo político-institucional em meio a regras vigentes que proibiam a reeleição nunca é demais ressaltar; não criou nem fortaleceu qualquer mecanismo institucional de fiscalização; sequer obrigou os governantes recandidatos a se licenciarem enquanto concorriam ao cargo que estavam ocupando. Em outras palavras, inseriu nova lógica ao sistema político, com efeitos profundos nos partidos e nas eleições, sem qualquer mecanismo de controle e, mais grave, sem alterar as regras norteadoras do modus operandi da vida política. Tratou-se de verdadeiro casuísmo, sem qualquer responsabilidade quanto a seus efeitos, mas com impactos sentidos fortemente desde que fora introduzida.

Tudo somado, as "políticas públicas" de cunho transformador são, estruturalmente, limitadas não apenas pelo modelo de acumulação, mas pela própria lógica do sistema político.

Afinal, só chegam ao poder (Executivo e Legislativo) os partidos políticos que obtêm financiamento privado (legal e ilegal), uma vez que o altíssimo valor das campanhas eleitorais exclui, de saída, grande parte dos partidos que não jogam "as regras do jogo" (o fundo partidário nem de longe cobre o valor das milionárias campanhas). Mais ainda, para ganhar eleições são necessárias coalizões que implicam, anteriormente a elas, a soma de minutos no horário eleitoral gratuito no rádio e na televisão - daí os acordos com partidos das mais diversas linhagens ideológicas, com compromissos igualmente diversos. Da mesma forma, para governar há a necessidade imperiosa de negociação de maiorias confortáveis nos respectivos Parlamentos (Câmara de Vereadores, Assembleias Legislativas e Congresso Nacional) com vistas à aprovação de medidas, ações e "políticas públicas" capitaneadas pelo chefe do Executivo e para garantir aquilo que se tornou uma espécie de "cláusula pétrea informal" do sistema político: a chamada "governabilidade".

Como a esmagadora maioria dos grandes e médios partidos - que carreiam candidatos ao Executivo e ao Legislativo - é financiada por grandes interesses (bancos, construtoras, entre outros setores empresariais sensíveis à ação estatal), governar implica fundamentalmente costurar acordos diversos e normalmente contraditórios. Mais ainda, a vida pública torna-se fortemente "privatizada", na medida em que interesse privados, notadamente empresariais, se fazem presentes antes, durante e depois das eleições, colocando a democracia brasileira, embora não apenas ela, sob suspeição plutocrática.

${ }^{6}$ Com o apoio entusiástico da grande mídia. 
Em outras palavras, seja para se eleger (papel do financiamento privado para fazer campanha e da coligação para obtenção de tempo no rádio e na televisão), seja para governar ("dívida" para com os financiadores e necessidade de maioria parlamentar para governar), os partidos políticos necessitam, imperiosamente, negociar compromissos publicamente assumidos e mais especificamente o "programa" de governo. Isso significa a existência tanto de "políticas públicas" tímidas, por não incidirem vigorosamente nos interesses constituídos, como contraditórias, uma vez que voltadas a vários interesses, boa parte deles contraditórios.

Qualquer movimento governamental considerado "radical", em qualquer setor, tem como reprimenda, de um lado, a perda de maioria parlamentar, e, de outro, a oposição feroz da grande mídia: porta voz das classes médias superiores e do Capital, como se verá. Isso tudo acarreta a perda de condições de governo e de governabilidade, abrindo caminho para a derrota eleitoral na próxima eleição. Mesmo o apoio a demandas de movimentos sociais tidos como "radicais" é fortemente bombardeado pela mídia e pela "lógica conservadora do sistema político", que ameaça imediatamente com a "retirada de apoio". Note-se o ciclo vicioso que o sistema político impõe à lógica de governar.

Mas, se esse cenário é verdadeiro, como explicar os inequívocos avanços sociais vigentes há pouco mais de uma década? Antes de tudo, pela entrada do Partido dos Trabalhadores, até então um partido médio, no jogo político-institucional dos "partidos de poder", isto é, sua aceitação das "regras do jogo": financiamento privado de campanhas, coligações eleitorais e coalizões governamentais amplas e contraditórias, negociação do programa de governo e enfática mensagem, simbolizada pela "Carta ao Povo Brasileiro" (publicada em 22 de junho de 2002), de partido da "ordem constituída".

Tal reversão político-ideológica não impossibilitou os referidos avanços, sociais e institucionais, mas teve como preço a redenção partidária às regras do jogo, conforme mencionado, com todas as consequências amplamente conhecidas, assim como o compromisso de que as "políticas públicas" não seriam "radicais". Isso permitiu fazer reformas "por dentro" do sistema político, sem assustar as elites.

Nesse sentido, as "políticas públicas", em qualquer governo de qualquer partido, no Brasil, necessariamente são contraditórias, por mais avanços que possam produzir, como vêm produzindo. Tais avanços, contudo, ou são aquém do que potencialmente poderiam ser - por exemplo, o gasto com transferência de renda custa 10\% do pagamento dos juros da dívida interna, como se verá abaixo -, ou convivem com outras "políticas públicas" claramente conservadoras - por exemplo, apoio desmesurado ao agronegócio, não revisão dos efeitos da dívida interna, leniência quanto à pejotização dos trabalhadores, não enfrentamento do oligopólio da grande mídia, entre inúmeros outros exemplos.

Do ponto de vista institucional, a não reforma das regras do jogo político denota igualmente a dificuldade que os partidos têm de intentar "políticas públicas" substantivas e simultaneamente alterar o modus operandi do sistema político. Este representa, portanto, uma trava àquelas.

As reformas com potencial transformador ocorrem, portanto, pelas "bordas", sem assustar as elites. É o caso da ampliação do crédito, do poder de compra real do salário mínimo e da cesta básica, dos programas de transferência de renda, da ativação da economia interna, entre outros. É vedado, no entanto, incidir nas grandes fortunas, nos lucros e no ambiente de negócios (quanto a este, no sentido de redefinir suas regras de funcionamento no que tange à maior igualdade). Não deixa de ser impressionante o fato de o Brasil, apesar dos inúmeros avanços sociais verificados, ainda ostentar índices alarmantes de desigualdade.

O sistema político brasileiro constrange a todos os partidos políticos, especialmente aos que historicamente lutaram pela mudança "radical" na desigualdade social. As "políticas públicas" são, dessa forma, moldadas também de acordo com essa estrutura quase que inabalada do sistema político arquitetado pelo regime militar durante o governo do general Figueiredo.

Para que as "políticas públicas" sejam mais inclusivas, expressivas e "radicais" -no sentido de irem à raiz dos problemas com vistas a transformá-los -, e por se tratar de demanda histórica da sociedade brasileira, torna-se fundamental enfrentar os interesses constituídos que sustentam o sistema político brasileiro e travam 
as "políticas públicas" profundas. Para tanto, a reforma política, que há anos habita a agenda pública brasileira sem que se efetive, é igualmente fundamental para que as "políticas públicas" possam ter mais coerência, serem sistêmicas e, sobretudo, mais expansivas e transformadoras.

\section{Vetos e Bloqueios da Mídia às "Políticas Públicas" Transformadoras}

Muito se tem discutido sobre o papel da mídia no mundo contemporâneo, notadamente da segunda metade do século XX aos dias de hoje. Diversas disciplinas, como as Ciências Sociais, a História, a Economia, a Semiótica e obviamente a Comunicação, entre outras, têm se debruçado sobre os impactos da "sociedade midiática" nas mais distintas áreas, sobretudo no "inconsciente coletivo", tendo em vista a manipulação de valores e fenômenos e a indução de comportamentos políticos, sociais, econômicos, estéticos etc.

Individualismo, consumismo, hedonismo, descrédito na ação política coletiva e nas doutrinas políticas, reforço da ideologia do self made man, ênfase no mundo privado (notadamente na carreira profissional e na circunscrição família, familiares e amizades da "vida social") são algumas das características resultantes desse mundo atomizado, vigente em maior ou menor medida em todos os países, notadamente após a ascensão do neoliberalismo e o definhamento do socialismo soviético.

A partir da "revolução" digital dos anos 1990, novas questões vêm sendo levantadas, uma vez que as comunicações estariam passando por profundas transformações, apercebidas intelectualmente, contudo, de modo distinto: para alguns setores são vistas como potencialmente democráticas e, para outros, como controladoras e alienantes.

Para além da controvérsia, as chamadas "redes sociais" (caso do Facebook, por exemplo, que chegou ao incrível patamar de 1 bilhão de perfis em 2012, isto é, 1/7 da população humana), "convergência digital" e ampla disponibilidade de comunicação não têm alterado de maneira significativa a ação política coletiva das sociedades, uma vez que o uso privado para fins de entretenimento e relações estritamente privatistas, familiares e de "grupos de afinidade" pessoais são sua característica. Apenas mobilizações pontuais, pouco significativas tendo em vista a dimensão planetária das comunicações, têm sido observadas, o que se deve, aparentemente, embora não apenas, ao legado individualista e alienante da dominação midiática instaurada desde a metade do século passado, e mais especificamente ao legado neoliberal da década de 1980.

No Brasil, onde a própria urbanização se confunde com a indústria midiática - o rádio e depois a televisão -, os meios de comunicação foram se desenvolvendo sem regulação, isto é, como negócio privado sem responsabilização quanto a seus efeitos públicos, o que inclui o não enfrentamento dos regimes políticos dominantes. Em particular, o regime militar pós-1964 foi responsável pela verdadeira tragédia comunicacional que vive o país em pleno século XXI, na medida em que incentivou o sistema oligopólico em que vivemos - em nome da "integração nacional" - e permitiu aos empresários da comunicação tratarem as empresas deste ramo, ironicamente chamadas de "comunicação social", como mero negócio privado, desde que convergente aos objetivos do poder dominante, entre os quais a ovação ao regime militar e a alienação político-cultural ${ }^{7}$.

O autoritarismo político, obtuso por excelência, permitiu e conviveu com a "censura do mercado" ao dar e renovar concessões a empresas de comunicação que, para se manterem, precisavam apenas adotar o

7 A grande mídia, no Brasil, historicamente foi partícipe ativa do jogo político e parte atuante no sistema político, como o comprovam o apoio ativo a ações golpistas na vida política do país. Paradoxalmente, não houve nenhum movimento significativo, desde a redemocratização nos anos 1980, no sentido do enquadramento da mídia nas regras do Estado de Direito Democrático, o que denota sua ação para além dos marcos legais (ausência de marco regulatório, de direito de resposta, de regras claras quanto à concessão e renovação das concessões etc., e sobretudo a possibilidade de prejudicar pessoas e instituições sem que seja responsabilizada). 
servilismo ao regime. Em vários casos, sendo o mais significativo o da Rede Globo - emissora gestada no ventre do militarismo -, o servo foi mais realista do que o rei, isto é, autocensura e adesão "ideológica" ao regime, com toda sorte de benefícios empresariais, deram contornos a uma corporação que se tornou a quinta maior empresa de comunicação, em faturamento, no mundo. Talvez mais importante, e ainda sem estudos suficientes a respeito, o papel das Organizações Globo na vida brasileira: de dimensão desconhecida, vai além da própria rede de televisão, na medida em que seus impactos são sentidos nos planos cultural e comportamental - tomados aqui em sentido gramsciano. O conglomerado das Organizações Globo, como se sabe, inclui um sem número de emissoras de rádio (AM e FM), transmissoras e retransmissoras de televisão, jornais e revistas, indústria fonográfica, uma fundação (que leva o nome de seu patrono, Roberto Marinho) com capacidade para financiar e induzir a produção cultural - com as devidas deduções tributárias -, parcerias internacionais e um satélite próprio para seus negócios, entre outras atividades corporativas.

De certa forma, a "vida cultural" (criação de padrões estéticos em diversas áreas, notadamente com viés estadunidense, "integração" nacional baseada em parâmetros pré-determinados) e "política" (clara interferência em eleições e nos centros decisórios estatais) brasileiras se tornam incompreensíveis se não se dimensionar o papel das Organizações Globo, que habilmente souberam se adequar tanto à ditadura quanto à democracia pós-1989. Por mais que partidos de oposição à ditadura e mesmo às Organizações Globo tivessem chegado ao poder após a redemocratização, jamais houve combate efetivo ao seu poder. A indigência comunicacional que experimentamos, com efeitos culturais - hegemônicos, portanto - mais profundos do que os de estirpe político-eleitoral, contribuiu para sedimentar um padrão comportamental do brasileiro "médio" cuja marca é a ideologia do "individualismo meritocrático" e a descrença nas transformações políticas coletivas, assim como nas instituições políticas.

Pois bem, a experiência, agora em seu terceiro governo, da gestão do PT no Governo Federal tem transformado parcialmente essas assertivas. No entanto, marcam-na negativamente o não enfrentamento ao oligopólio midiático, a não colocação na agenda governamental de um marco regulatório da mídia e a não revisão das regras de renovação das concessões, o que representa, em outras palavras, a permanência da não democratização da informação e da comunicação - diferentemente de nossos vizinhos argentinos - e, consequentemente, a manutenção de uma "democracia parcial". Apesar disso, diversas "políticas públicas" sociais, como se viu, têm se desenvolvido e alterado a vida de milhões de brasileiros.

Observa-se, portanto, certa desconexão entre mudanças incrementais e não "radicais", mas, ainda assim, inéditas e socialmente impactantes (caso de programas como o Bolsa Família no contexto do Sistema Único de Assistência Social, e de uma série de programas específicos nas áreas de habitação, energia, saúde, educação, crédito e outras) e a resistência elitista e conservadora da grande mídia comercial.

As grandes corporações midiáticas, que expressam os interesses materiais e ideológicos das classes médias e do capital, embora críticas às transformações coletivas promovidas pelas "políticas públicas" federais, na medida em que vão em direção contrária ao mundo "dos melhores e dos mais capazes, venham de onde vierem" (mote histórico do jornal $O$ Estado de São Paulo), as aceitaram por não confrontarem a estrutura de poder e a dinâmica das propriedades "empresarial" (o que inclui a própria mídia), "agrária" e do "mercado financeiro".

A convivência entre reformas sociais - ordenadas - e status quo se mantém, apesar do elitismo oposicionista dos meios de comunicação, uma vez que atuam como verdadeiros "aparelhos privados de hegemonia" e "intelectuais coletivos": categorias gramscianas cada vez mais observáveis na cena político-midiática brasileira. Tal modus operandi coloca a mídia como organizadora das classes médias e do Capital Global, obstruindo e vetando "políticas públicas" tidas ou apercebidas como "inaceitáveis". O caso da chamada "mobilidade urbana" é notório, conforme apontado aqui, uma vez que sequer ascende à agenda o tema do necessário privilegiamento, nas grandes metrópoles, das vias públicas ao transporte coletivo. A indústria automobilística, que financia campanhas de parlamentares e chefes de Executivos, patrocina vigorosa e generosamente os meios de comunicação e adota estratégias de marketing extremamente agressivas, entre outras estratégias, tem na mídia seu "intelectual coletivo" capaz de vetar qualquer mudança significativa nas "políticas públicas" urbanas. O mesmo ocorre quanto ao Estado, interessado nos tributos advindos da cadeia 
produtiva do automóvel, apesar de suas consequências nefastas. E, também, quanto ao "mercado imobiliário", altamente especulativo, capaz de transformar as cidades em verdadeiras "selvas de pedra", e ao "mercado financeiro", capaz de sobreviver com os juros seguros da dívida interna e manter uma elite rentista, como se verá abaixo.

A grande mídia comercial brasileira - composta por organizações complexas de emissoras de rádio e televisão, de jornais e revistas, de portais na internet com conteúdos diversos e lucrativos, entre outras atividades empresariais - veta e obstrui, por meios diversos, qualquer transformação "significativa" no que tange às "políticas públicas". O caso do imposto sobre as grandes fortunas é outro dos temas tabus, pois, ao incidir sobre o grande capital, sequer consegue chegar à agenda de discussão. A mídia, portanto, apenas aceita, mesmo que a contragosto, mudanças incrementais e consideradas "laterais", caso dos programas sociais vigentes.

Mas, quando uma dada política contrária aos interesses midiáticos é inserida na agenda governamental, há uma enorme mobilização no sentido de vetá-la ou, se não for possível, conformar, enquadrar o "desenho" desta política, isto é, sua "formulação" e seus objetivos quanto ao que se pretende alcançar, a ponto de tornálos inócuos ou minorados.

Tal mobilização conta com entrevistados "especialistas" que "autorizam" uma dada posição, com todo o aparato de manchetes, fotos, charges e matérias que expressam opinião e que, por seu turno, se espraiam sutilmente pelas coberturas. Embora o discurso midiático advogue, como uma cantilena, a separação entre coberturas jornalísticas e opinião, o que se vê fundamentalmente é uma mesma linhagem ideológico-editorial corroborar o modus operandi dos "aparelhos privados de hegemonia", como já aludido, uma vez que atuam com o objetivo de vetar e de propor políticas, sempre por caminhos distintos: ora ostensivos, ora subliminares.

A própria aceitação do poder oligopólico da mídia demonstra a incapacidade política do Estado brasileiro em enfrentar tais poderes constituídos, o que o obriga a atuar nas margens e frestas da estrutura econômica e social brasileira. Daí o incrementalismo das "políticas públicas" desenvolvidas em pouco mais de uma década, que, reitere-se, por mais importantes e significativas que sejam, são tímidas perante os recursos econômicos disponíveis e, sobretudo, perante as necessidades de milhões de brasileiros. Basta comparar os gastos sociais brasileiros com as necessidades populares e mesmo com países similares para que se compreenda o espaço que se tem para transformações profundas.

É claro que somente "vontade política" dos governantes não é suficiente para alterar realidades historicamente constituídas. É necessária uma conjunção de fatores, tais como, além da vontade política, capacidade técnico-política de governar, reordenamento orçamentário, reforma política, mobilização e pressão social, entre outros fatores. Sem isso, o enfrentamento aos grandes poderes, notadamente da mídia, do latifúndio (organizado em torno do agronegócio), dos capitais produtivo e financeiro especulativos (cada vez mais articulados), entre outros, será sempre protelado.

Os vetos e obstruções da mídia oligopólica a "políticas públicas" profundas e transformadoras reafirmam seu caráter político (da mídia) e a constatação de que é parte constitutiva do Sistema Político.

Uma "janela de oportunidade" à reforma do sistema midiático parece se abrir quando "políticas públicas" sociais, apesar da oposição vigorosa de grande parte de seus órgãos, vêm sendo implementadas em perspectiva federal - SUAS; Luz para Todos; Minha Casa, Minha Vida; vasta concessão de crédito, valorização do salário mínimo, aumento do poder de compra da cesta básica, programa de cisternas, entre outras - e aparentemente ganham estatuto de "políticas de Estado", dada a legitimação que adquiriram. Ao se instituírem como "políticas de Estado" diminuem o poder histórico dos veículos de comunicação de derrogálas, o que por si só é um fenômeno sociopolítico significativo.

Portanto esse processo vem provocando uma inédita desconexão entre o poder de audição da mídia e a realidade social da massa de trabalhadores pobres no Brasil. Desde o episódio do chamado "mensalão", essa 
desconexão vem se aprofundando, tornando o Governo Federal e seu principal partido imunes, de certa forma, aos ataques e campanhas da mídia - apesar de suas contradições. Tal fato pode ser constatado nas eleições de 2012, quando, em meio ao julgamento midiático do "mensalão" pelo Supremo Tribunal Federal, o PT saiu-se como um dos grandes vencedores. Independentemente do partido político utilizado como exemplo, o fato marcante é que a disjuntiva sociedade/meios de comunicação vem se aprofundando no país, o que merece ser analisado com maior acuidade ${ }^{\mathbf{8}}$.

Desse modo, aparentemente panfletos ideológicos, caso paradigmático da revista Veja, se circunscrevem num mesmo público, numericamente diminuto e com influência decrescente. Mesmo as Organizações Globo, embora ainda bastante poderosas, veem seu poder decrescer.

"Políticas públicas" transformadoras podem, portanto, se desenvolver, alterando a vida de milhões de brasileiros, se os tomadores de decisão comprometidos com transformações compreenderem essa desconexão e aproveitarem a "janela de oportunidade" constituída pela conjunção de: apoio social (legitimidade) e político (notadamente eleitoral) da grande massa dos pobres, mesmo que fragmentada; decréscimo relativo do poder midiático; recuo institucional das forças militares aos quartéis; conjuntura internacional favorável a reformas sociais; o fato de o Brasil ser considerado internacionalmente um caso de sucesso em termos de "reformas dentro da ordem", num cenário de potencialidades econômicas. Tudo isso aponta para uma nova correlação de forças em que, por dentro e por meio das regras democráticas, possa haver o enfrentamento aos poderes, até então intocáveis, "radicalizando" a democracia pela via da ampla redistribuição da renda, da terra, da mídia e dos capitais especulativos, paralelamente ao aprofundamento da democracia participativa e da transparência do Estado.

Oportunidades como a que se vivencia no momento podem passar, o que evidencia a necessidade de um projeto de nação estratégico capaz de consolidar avanços e estabelecer novas regras ao jogo democrático. Caso contrário, o país continuará pautado pelas velhas e conservadoras elites, das quais a grande mídia faz parte.

\title{
"Políticas Públicas" e Conjuntura Política: o Significado de "Fazer Mais" no Embate Político Contemporâneo
}

\begin{abstract}
Rendimentos do trabalho explicam 58\% da queda do índice de Gini entre 2001 e 2008, sendo $19 \%$ dela explicada por aumentos dos benefícios da previdência social e $13 \%$ pelo Bolsa Família. Cada ponto percentual de redução do Gini pelas vias da previdência custou $352 \%$ mais que o obtido pelas vias do Bolsa Família. Note que todas essas transferências cresceram no período. Ou seja, a desigualdade poderia ter caído ainda mais se fizéssemos a opção preferencial pelos pobres pelas vias do Bolsa Família”. (IPEA, 2012, p. 40, grifo nosso)
\end{abstract}

O atual e precipitado debate sobre a sucessão à presidência da República - precipitação cujas raízes estão na emenda da reeleição - no que se refere a "fazer mais", "ir além do que já se fez" nas "políticas públicas", parte de uma base comparativa significativa: o país ostenta índices sociais progressivamente positivos, cujos impactos são sentidos no cotidiano do cidadão pobre.

Deve-se ressaltar que os avanços sociais que vêm ocorrendo no Brasil, parte deles introduzidos pela Constituição de 1988 e aprofundados, sobretudo, com o governo Lula, são insofismáveis, uma vez que, por um lado, deram sequência à efetivação da "lógica dos sistemas" de seguridade (Sistema Único de Saúde;

\footnotetext{
${ }^{8}$ Devem-se ressaltar importantes ações do governo Lula no sentido de minorar o poder da mídia: pulverização da propaganda federal, criação da Empresa Brasileira de Comunicação, promoção da Primeira Conferência Nacional de Comunicação e tentativa, frustrada, de criação de uma agência reguladora. Embora importantes, foram claramente insuficientes e tímidas.
} 
Sistema Único de Assistência Social; Fundef/Fundeb; Sistema Único de Segurança Pública - este, na lógica maior da segurança como "defesa social"; Leis Nacionais voltadas a políticas setoriais em diversas áreas), e, por outro lado, inauguraram um inédito processo de transferência de renda por meio de diversos mecanismos: particularmente o Programa Bolsa Família, mas também (como se viu) a ampla concessão de crédito, a valorização inédita do poder de compra do salário mínimo e da cesta básica, acesso às universidades - privadas e públicas, com expansão destas últimas -, entre outras políticas exitosas.

Todos esses avanços - eivados de problemas e contradições -, que têm promovido significativa mobilidade social no Brasil, se juntam à ativação da economia mesmo em tempos de crise internacional, o que é demonstrado pela (aludida) imensa formalização do trabalho, pelo intenso consumo interno e por grandes "políticas públicas" federais no contexto dos Planos de Aceleração do Crescimento.

Pode-se dizer que, de maneira progressiva, o país tem caminhado rumo à efetivação de um Welfare State, na medida em que a Seguridade Social combina ações preventivas e compensatórias (caso dos seguros) e focalizadas e universalizantes (caso, respectivamente, de bolsas de transferência de renda e dos direitos como saúde, educação etc.), em que a previdência social, a saúde, o seguro desemprego, a transferência de renda e o poder de compra são seus sustentáculos.

Tem-se, portanto, uma nova realidade social, gestada fundamentalmente há pouco mais de dez anos - com fios condutores em 1988 -, mas que contrasta, conforme exposto, com a grotesca interpretação manipulatória da mídia, uma vez que procura sistematicamente negá-la, diminuí-la ou desacreditá-la, em vez de apontar seus limites e alcances.

Ressalte-se que o gasto social total vem sendo ampliado, notadamente desde os governos Lula, no entanto, conforme aludido, quando cotejado com a dimensão histórica da desigualdade brasileira, ainda está aquém das necessidades de um país que pretende simultaneamente extinguir a miséria e consolidar um Estado de Bem Estar Social.

Já a contraface das "políticas públicas" sociais exitosas está no gasto financeiro com a dívida pública interna. Segundo Fagnani (2001):

\begin{abstract}
A agenda brasileira para o futuro, definitivamente, não é aquela que os organismos internacionais querem impor ao mundo. Nosso desafio central é consolidar as conquistas de 1988, bem como os avanços e convergências obtidos recentemente. Isso depende de uma duríssima corrida de superação de obstáculos. Um deles é a redução das despesas financeiras, o maior item do gasto público. Somos líderes mundiais em taxa real de juros e vice-líderes no ranking de maiores pagadores de juros em proporção do PIB. Se Macunaíma vivesse hoje, certamente diria: 'Ou o Brasil acaba com os juros, ou os juros acabam com o Brasil!'
\end{abstract}

O gasto apenas com o serviço da dívida pública, isto é, os juros - sem, portanto, diminuir o principal -, atinge mais de 200 bilhões de reais ao ano, cifra incrivelmente alarmante, mesmo se levarmos em consideração a melhoria recente no seu "perfil", assim como sua melhor posição relativa perante outros países, por dois motivos: a) cerca de $80 \%$ deste valor pertence a 20.000 proprietários distintos que, dessa forma, se beneficiam vigorosamente com a alta dos juros; b) o Programa Bolsa Família, política pública exitosa e recomendada por instituições internacionais como a Unesco, que paga benefícios de cerca de 300,00 reais por família (teto), sendo o valor médio metade disso, representa apenas cerca de $0,4 \%$ do PIB, embora atinja cerca de 13 milhões de famílias (número em ascensão em razão do Programa Brasil Carinhoso).

Em outras palavras, deve-se considerar que "é possível fazer mais", "ir além" nas "políticas públicas" ao se inverter a equação entre "gasto social" e, no interior deste, o percentual de transferência de renda em relação ao PIB, e "gasto financeiro" com o pagamento de juros da dívida interna. 
Mesmo não sendo decisão simples, que dependa apenas da vontade política, o fato é que o enfrentamento aos poderes privados constituídos é tarefa crucial de governos comprometidos com a democracia, notadamente a democracia de "caráter popular e social", sem a qual a própria "democracia política" (dissensos, conflitos, circulação do poder etc.) torna-se mera formalidade. Enfatize-se que a democracia perdeu seu sentido exclusivamente político - as "regras do jogo" no dizer de Bobbio (1986) -, tornando-se simultaneamente política e social, no final do século XIX, quando as primeiras reformas sociais foram implementadas na Europa. O Brasil somente agora vem consolidando o que se iniciou nos anos 1930/40, durante a Era Vargas, o que é, portanto, uma experiência histórica não apenas brasileira, mesmo que interrompida, como também notadamente da Europa do pós-guerra.

Dessa forma, pode-se dizer que é possível "fazer mais" do ponto de vista fiscal, tributário e orçamentário sem o que as "políticas públicas" como um todo e as sociais em particular tornam-se meros apêndices -, o que implica fundamentalmente enfrentar os grandes poderes constituídos, como afirmado aqui. Estes podem ser sintetizados da seguinte forma: os aludidos detentores da dívida pública; o sistema financeiro como um todo, notadamente os bancos; os setores do capital que se beneficiam de dinheiro público sem contrapartida ao desenvolvimento social do país (agronegócio, grandes tomadores de empréstimos do BNDES e da CEF, entre outros); a grande mídia, como empresa e como "aparelho privado de hegemonia" que vocaliza interesses das classes médias e superiores; as grandes empreiteiras, com seus contratos bilionários e bastidores opacos; o sistema político, fortemente "privatizado", por meio do financiamento privado legal e, sobretudo, ilegal, proveniente das grandes empresas.

Embora a lista seja maior do que essa, e haja poderes intermediários, seu enfrentamento inteligente e politicamente hábil permitirá se "fazer mais" do que se fez na última década. Esse enfrentamento pode ocorrer, entre outras formas, com o apoio dos movimentos sociais, por meio de canais institucionais de participação política e com a ampliação "radical" da transparência de forma a, progressivamente, alterar as "regras do jogo".

"Fazer mais", portanto, implica a alteração do cerne fiscal-tributário-orçamentário - cujos números acerca dos juros da dívida pública contrastam incrivelmente com os da transferência de renda, como já visto - e da maneira como o "jogo político" se desenvolve, o que leva à necessidade imperiosa, em termos teóricos e empíricos, de reforma política: com vistas a enfrentar a privatização da vida política, os grandes poderes constituídos, o sistema midiático oligopolizado e oligarquizado, entre outras reformas que objetivem, reiterese, "radicalizar" a democracia.

Trata-se de demanda histórica dos movimentos sociais que lutaram pela democratização da sociedade brasileira e do pensamento democrático como um todo, o que inclui necessariamente as universidades e centros de pesquisa comprometidos com a democracia política e social. Para tanto, somente "políticas públicas" consistentes, sistêmicas e transformadoras serão capazes de reverter, mesmo que no médio prazo, a abismal desigualdade socioeconômica e política, entre outras, que ainda vigem na sociedade brasileira.

\section{Considerações Finais}

Neste texto, constituído por partes que originalmente foram escritos como artigos voltados ao debate público, objetivou-se analisar algumas dimensões críticas acerca do conceito e da práxis das "políticas públicas".

Ao repensar e retrabalhar cada parte, cuja reunião forma um todo - até porque foram originalmente escritas em forma de sequência analítica -, procurou-se trazer à tona questões e problemas não usualmente predominantes nas linhagens teóricas e mesmo empíricas das "políticas públicas". Igualmente, é importante referendar a fronteira em que está situado este artigo: entre a análise conceitual e o debate público quando o tema refere-se às "políticas públicas". 
Diversas questões advieram dessas análises, a começar pela forma como o texto está organizado: análise conceitual com base na constatação de que o cerne das "políticas públicas" é negligenciado, isto é, os conflitos, demonstrados empiricamente; os constrangimentos do modelo de acumulação flexível à efetivação de "políticas públicas" transformadoras; o papel modelador do sistema político perante as "políticas públicas"; os vetos interpostos pela mídia ao agendamento, formulação e execução das "políticas públicas"; e, por fim, análise conjuntural do embate sobre "fazer mais" em "políticas públicas". Tais temas reafirmam a sequência lógico-analítica de tais políticas e se articulam na perspectiva da reflexão crítica acerca das dimensões aludidas quanto ao fenômeno das dimensões das políticas públicas.

Deve-se ressaltar que os problemas analisados levam a concluir que "políticas públicas" representam uma terminologia de uso relativamente recente no Brasil e que a maior parte da produção teórica advém do exterior, o que implica tanto a ausência de particularidades acerca da realidade brasileira (instituições, modelos organizacionais, cultura política, arquitetura legal e institucional, entre outros) como a tendência de se analisar as "políticas públicas" nacionais (processo decisório, estrutura de formação de demandas, alianças entre os atores etc.) na ótica de outras realidades. Não se advoga, com isso, qualquer bloqueio ao que se produz em outras realidades, assim como se reconhece o mérito que muitas das teorias produzidas possuem ao subsidiar análises sobre a realidade de qualquer "política pública".

O problema reside na adoção, sem critérios, tanto da terminologia "políticas públicas" como de modelos conceituais que, por vezes, ou são incabíveis ou incapazes de se adaptar a instituições, arenas, atores, marcos legais, cultura política, entre outros fatores e marcos conceituais, típicos da realidade brasileira. Não se aceitam, aqui, nem a máxima de que, essencialmente, os fenômenos são os mesmos em todos os lugares, cuja consequência é a onipotência teórica, nem seu oposto, isto é, que cada realidade é uma particularidade jamais generalizável ou sem "fios condutores". Há, certamente, espaços intermediários entre ambas as perspectivas.

Isso implica a necessidade de constante olhar crítico, como forma de adaptar às condições nacionais o que é observado em realidades distintas, assim como de se refletir sobre temas e questões negligenciados, caso das seções em que está organizado este texto. No caso específico do "modelo de acumulação", se trata de abordagem clássica nas ciências sociais (teóricas e aplicadas), mas que praticamente desapareceu do cenário intelectual; sua utilização impacta as análises que, dessa forma, vão além das instituições e dos atores.

Neste texto, procurou-se refletir sobre conceitos e sobre questões pertinentes à realidade brasileira, notadamente naquilo que se configura, do ponto de vista aqui adotado, como ausências. O caráter ensaístico aqui empregado é devido tanto à reflexão original voltada ao debate público, conforme aludido, como pelo fato de ser uma tentativa de ir além do razoavelmente conhecido em "políticas públicas". Outros estudos, de naturezas variadas, devem dar sequência a essa tarefa, uma vez que termos/conceitos amplos e fugidios tendem muito mais a encobrir do que a esclarecer sobre o conhecimento das realidades, entre as quais se destaca a predominância das "políticas públicas".

\section{Referências}

BOBBIO, N. O futuro da democracia - uma defesa das regras do jogo. Rio de Janeiro: Paz e Terra, 1986.

CASTELLS, M. O poder da identidade. São Paulo: Paz e Terra, 2000.

FAGNANI, E. "As lições do Desenvolvimento Social Recente no Brasil”. Le Monde Diplomatique Brasil, 01 de dezembro de 2011, n. 53. Disponível em: http://www.diplomatique.org.br/artigo.php?id=1060. Acesso em: 05 jun. 2013.

FONSECA, F. O consenso forjado - a grande imprensa e a formação da agenda ultraliberal no Brasil. São Paulo: Hucitec, 2005. 
HALL, P.; SOSKICE, D. (Orgs.). Varieties of capitalism: the institutional foundation of comparative advantage. Oxford University Press: Oxford, 2001.

HARVEY, D. The condition of postmodernity: an enquiry into the origins of cultural change. Cambridge: Blackwell, 1990.

HIRSCHMAN, A. A retórica da intransigência: perversidade, futilidade, ameaça. São Paulo: Cia. das Letras, 1985.

IPEA. A Década Inclusiva (2001-2011): Desigualdade, pobreza e políticas de renda. Comunicados do IPEA, n. 155, Brasília, IPEA, 25 set. 2012.

LE MONDE DIPLOMATIQUE BRASIL. Disponível em: www.diplomatique.org.br. Acesso em: 05 jun.2013.

LINDBLOM, C. The science of 'muddling through'. Public Administration Review, v. 19, n. 2, p. 79-88, 1959.

OFFE, C. Problemas estruturais do estado capitalista. Rio de Janeiro, Tempo Brasileiro: 1984.

PORTAL CARTA MAIOR. Disponível em: www.cartamaior.com.br. Acesso em 05 jun.2013.

RIFKIN, J. O fim dos empregos: o declínio inevitável dos níveis dos empregos e a redução da força global de trabalho. São Paulo: Makron Books, 1995.

SENNETT, R. The corrosion of character: the personal consequences of work in the new capitalism. London: W. W. Norton, 1998. 